\title{
Test facilities for SCORE-D
}

\author{
Dirk Greuel • Jan Deeken • Dmitry Suslov • \\ Klaus Schäfer · Stefan Schlechtriem
}

Received: 21 January 2013/Revised: 11 April 2013/Accepted: 12 April 2013/Published online: 22 May 2013

(C) The Author(s) 2013. This article is published with open access at Springerlink.com

\begin{abstract}
The $\mathrm{LOX} / \mathrm{LH}_{2}$ Staged Combustion Rocket Engine Demonstrator (SCORE-D) is part of ESA's Future Launcher Preparatory Program (FLPP). SCORE-D serves as a technology demonstrator in perspective of the development of the High Thrust Engine (HTE), which is designated as a candidate for the main stage engine of the Next Generation Launcher (NGL). To develop and test the SCORE-D engine, ESA investigates configurations of the test benches P3.2 and P5 at DLR test site in Lampoldshausen. For the SCORE-D Hot Combustion Devices (HCD) development, i.e. Pre-burner (PB) and thrust chamber assembly (TCA), the P3.2 test facility has to be modified for further usage. Recently, the first steps in this endeavor have been made with the evaluation of the necessary modifications to the facility. To accommodate the SCORE-D engine, it is foreseen to modify the P5 test facility in the coming years. In the last year, DLR has started the design phase for these modifications. In preparatory test programs at the P8 test facility, Astrium has conducted sub-scale hot combustion devices tests. While Astrium designed and manufactured the sub-scale assembly of the pre-burner and the main combustion chamber (MCC) for SCORE-D, DLR operated the P8 test facility.
\end{abstract}

Keywords Future Launchers Preparatory Program . Next Generation Launcher · High Thrust Engine . Staged Combustion Rocket Engine Demonstrator . Test facilities · DLR Lampoldshausen

This paper is based on a presentation at the German Aerospace Congress, September 10-12, 2012, Berlin, Germany.

D. Greuel $(\bowtie) \cdot$ J. Deeken · D. Suslov · K. Schäfer .

S. Schlechtriem

DLR, German Aerospace Center, Institute of Space Propulsion, 74239 Hardthausen, Germany

e-mail: Dirk.Greuel@esa.int

\author{
Abbreviations \\ $\mathrm{CC} \quad$ Combustion chamber \\ FLPP Future launchers preparatory program \\ GS Gimbal system (e.g. Cardan) \\ HCD Hot Combustion Devices (PB + TCA) \\ HGV Hot gas valve \\ HPFTP High pressure fuel turbo pump \\ HPOTP High pressure oxygen turbo pump \\ HTE High thrust engine \\ INJ Injector head \\ IS Ignition system \\ JANNAF Joint Army, Navy, NASA, Air Force \\ JPT Joint Propulsion Team (Avio SpA, Astrium \\ GmbH, SNECMA Safran Group) \\ MCC Main combustion chamber (INJ + CC) \\ MCCM Measurement, control, command and \\ monitoring \\ NCFAU Nozzle Coolant Flow Adjustment Unit \\ NE Nozzle extension \\ NGL Next generation launcher \\ PB Pre-burner \\ PBOV Pre-burner oxygen valve \\ SCORE-D Staged Combustion Rocket Engine \\ Demonstrator \\ TC Thrust chamber (IS + MCC + NE) \\ TCA Thrust chamber assembly (GS + TC) \\ w/o Without
}

\section{Introduction}

Almost all of DLR Lampoldhausen's research and development programs directly support European rocket engine development programs, especially ESA's FLPP program to investigate the HTE for the NGL [1]. 
The key technology is combustion, and it is well understood in the scientific community that the control and management of the exceptionally high power densities in rocket combustors is of peak importance. The governing equations which are used to model the multiple complex interacting processes in combustion chambers are highly non-linear and, therefore, extremely difficult to solve. While the application of computational fluid dynamics CFD and other improved modeling techniques in areas of compressor and turbine development paved the way to keeping expensive testing at a minimum, the control of combustion phenomena is still based purely on empiricism. Combustion modeling is currently only used to support the understanding of combustion chamber phenomena, like heat transfer or combustion instabilities, but up to now only semi-empirical methods have been used to design components like injectors, swirlers or the complete layout of a combustion chamber. The only possibility to tune the chemical combustion process is still solely by extensive testing in an environment of total quality control. This still holds for component tests on single injector elements as well as complete rocket engines with power head and nozzle.

The European research facility P8 shared by CNES, SNECMA, Astrium and DLR has been used for conducting sub-scale hot combustion devices tests. This development is the basis for the studies at P3.2 and P5 for thrust chamber and engine tests of SCORE-D. The current status is presented in the following chapters.

\section{The SCORE-D engine}

From system engineering point of view [2], the basic features of the engine are a serial staged combustion cycle architecture which comprises of a:
- fully regeneratively cooled TCA,

- single fuel-rich pre-burner,

- turbo machinery with two parallel high pressure turbo pumps (HPTPs): HPFTP and HPOTP,

- control strategy based on the use of the pre-burner oxygen valve (PBOV) and a hot gas valve (HGV) downstream of the pre-burner for throttling and mixture ratio trimming.

Both valves PBOV and HGV used for engine control are among the six main valves shown in Fig. 1 which are electrically actuated. As a baseline, the $\mathrm{LOX} / \mathrm{LH}_{2}$ engine shall produce 140 tons nominal vacuum thrust at a reference combustion chamber pressure of 150 bars to be compatible with existing European test benches. At a Demonstration Logic Key Point held in January 2012, an engine test logic was defined, in which the various test configurations have been assigned to specific test benches:

- $\mathrm{PB}$ stand-alone tests followed by PB/TCA coupled tests at P3.2.

- HPFTP and HPOTP stand-alone tests at PF52.

- Engine tests at P5.

and necessary modifications of the selected tests benches have been assessed.

As part of its contribution to FLPP, the DLR operates the test facilities P3.2 and P5 at the test site in Lampoldshausen for the testing of the staged combustion demonstrator. In addition to the test bench operation, DLR supports the mastering of staged combustion engines in Europe within the frame of its own basic research, placing the focus on introducing new technologies, such as the injection system reported on in Sect. 3, and on improving their maturity level.

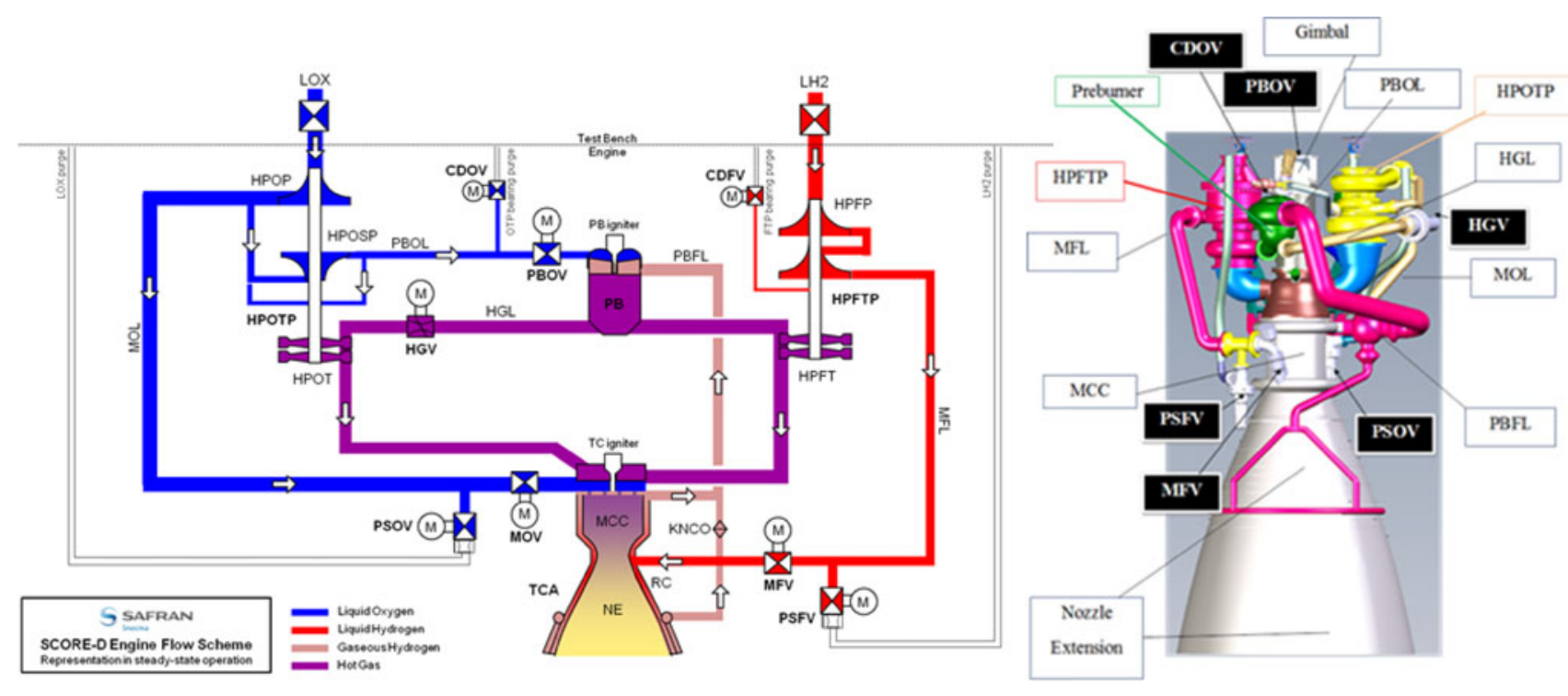

Fig. 1 SCORE-D engine flow scheme (left) and Mock-Up (right); courtesy of SAFRAN 


\section{DLR API/BKI tests at P8 test facility}

In parallel and in coordination with the described FLPP activities, the P8 test facility has been used by DLR in national frame in February 2012 for testing its new injection system for high pressure combustion up to more than 330 bars.

Injector design is of utmost importance for performance and combustion stability. Optimized designs have to provide high combustion efficiency at a minimum chamber length in combination with a low propellant pressure drop across the injector and with low manufacturing costs of it.

The next generation of European launchers will most probably employ engines operating at higher chamber pressures than the actual Vulcain II engine. This engine will either be operated as a gas-generator cycle or a fuelrich pre-burner cycle, depending on the design combustion chamber pressure and other system considerations. The injection conditions for a pre-burner combustion chamber are quite different than for a main combustion chamber. Table 1 summarizes the operating conditions of some preburner combustion chambers.

The SSME uses two combustion chambers to individually supply the fuel and the oxidizer turbine. The maximum inlet temperature of the turbine is limited to $900 \mathrm{~K}$. This results in a maximum oxidizer to fuel ratio (ROF) of about 0.9 in contrast to mixture ratios between 5 and 7 typical for MCC injection. Depending on the actual engine cycle design, hydrogen injection temperatures can be as low as $50 \mathrm{~K}$. This is the case for the RD-0120. The hydrogen is supplied directly from the turbo pump to the pre-burner. These special conditions are known to increase the risk of combustion instabilities due to the injection of cold hydrogen with coaxial injectors, which are commonly employed for the propellant combination $\mathrm{LOX} / \mathrm{H}_{2}$.

The concept of porous injection has been investigated by DLR for the last decade. A typical API ("Advanced Porous Injector") consists of a porous face plate for the injection of the low-density hydrogen and a large number of small diameter tubes for the injection of the liquid oxygen. These LOX tubes have an inner diameter of $1.5 \mathrm{~mm}$ and are arranged in a non-impinging fashion. Such an injector head is illustrated in Fig. 2. The simplicity of this design offers a large potential for manufacturing cost savings. In contrast to a classical showerhead injector, fuel and oxidizer are in

Table 1 Operating conditions for existing pre-burners

\begin{tabular}{lll}
\hline Engine & PB pressure (bar) & PB mixture ratio \\
\hline RD-0120 & $\approx 475$ & $\approx 0.66$ \\
SSME & $\approx 430$ & 0.68 (fuel turbo pump) 0.95 \\
& & (oxidizer turbo pump) \\
\hline
\end{tabular}

direct contact immediately after injection. The flame is anchoring directly at the LOX post tip for typical injection conditions, which was shown by optical investigations. The large number of small diameter LOX jets injected in a hydrogen atmosphere drastically increases the initial contact surface between oxidizer and fuel compared to classical coaxial injectors.

The hydrogen pressure drop across the injector head is determined by the permeability of the chosen face plate material. Test runs at MCC conditions exhibited a stable combustion behavior at hydrogen pressure drops below $5 \%$ of the mean chamber pressure.

In existing rocket engines, a small amount $(<20 \%)$ of the fuel mass flow has been bled through the injector face for cooling purposes only. However, the main fuel mass flow was basically injected using classical coaxial injectors. This technique is also used in operational full-scale rocket engines like the RL10 and the SSME to cool down the injector head. A similar transpiration cooling method is used in the RD-0120 engine [3]. A small part of the fuel mass flow is fed through 20,000 holes of $0.2 \mathrm{~mm}$ diameter that are drilled in the faceplate. The new concept provides full fuel mass flow through the porous injector face. Pavli et al. [4] have used a similar design with a Rigimesh ${ }^{\mathrm{TM}}$ faceplate for subcritical $\mathrm{GOX} / \mathrm{GH}_{2}$ studies.

The present investigation focuses on the feasibility of the API injector concept at low-temperature, low-mixture ratio conditions typical for pre-burner combustion chambers. The pre-burner of an engine operating as a staged combustion cycle has to operate at chamber pressures considerably higher than those of the main combustion chamber. To simulate the conditions imposed by this cycle layout, a pre-burner chamber pressure in the range of 300 bars was assumed.

These conditions were investigated using an $80 \mathrm{~mm}$ diameter combustion chamber equipped with a porous injector. The hot fire tests were conducted at the European High Pressure Research and Technology Test Facility P8 at the DLR site of Lampoldshausen. For the investigations

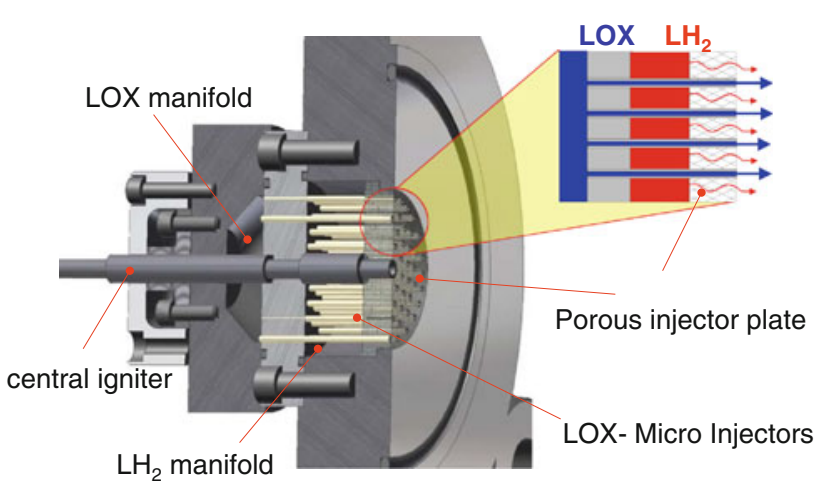

Fig. 2 Advanced porous injector (API) concept 
presented here a new subscale combustion chamber was designed. The test specimen design had to allow for the achievement of the following main test goals:

1. Operation of a porous injector at operating conditions realistic for PB applications.

2. Determination of the combustion efficiency.

3. Determination of the combustion stability and roughness.

4. Determination of the temperature stratification of the hot gas.

In addition to chamber pressure, mixture ratio and propellant inlet conditions, realistic operating conditions also include a realistic combustion chamber shape, which determines the flow field. Typical Mach numbers inside a pre-burner are considerably lower than in a main combustion chamber. The configuration presented here used a nozzle segment with an exchangeable throat. The throat segment tested was designed with a throat diameter of $14 \mathrm{~mm}$.

The determination of the combustion efficiency was based on the JANNAF recommendations [5]. For this reason, the static pressure was determined on various locations inside the combustion chamber. During previous campaigns with $80 \mathrm{~mm}$ subscale combustion chambers spontaneous combustion instabilities (1-T mode) occurred, which were never observed during campaigns with $50 \mathrm{~mm}$ diameter combustion chambers. This was attributed to the lower characteristic frequency of the 1-T mode, which occurs at about $12 \mathrm{kHz}$ for these chamber dimensions and hot gas properties. These instabilities were removed by a change in the LOX injector pattern. For the investigations presented here, an $80 \mathrm{~mm}$ chamber diameter was chosen. This allows for a direct comparison of the stability behavior between different injector head configurations and injection conditions. The combustion stability was determined using three dynamic pressure sensors located at multiple angular positions at an axial position $7.5 \mathrm{~mm}$ downstream of the injection plane. These pressure sensors were flush-mounted. Detailed analyses of the measurement accuracy are still in progress.

Another important parameter for pre-burner applications is the stratification of the hot gas atmosphere. The overall chamber ROF determines the mean temperature of the combustion gases. Non-perfect mixing, however, might cause streams of high temperature combustion gases to persist until the first row of blades of the turbine. In real pre-burner applications, this stratification is largely reduced by changes in flow direction between the preburner combustion chamber and the actual turbine inlet. Nevertheless, the spatial and temporal non-uniformity of the combustion gas temperature is a design parameter of an injection system for pre-burner applications. To measure this stratification, several thermocouples have been applied inside the combustion chamber at multiple radial and angular positions. An additional measurement ring was inserted directly upstream of the nozzle segment. This measurement ring featured three beams made of Inconel, which met in the chamber's centerline. The thermocouples were mounted at various locations on these beams. The application of thermocouples and the Inconel measurement ring was only possible due to the comparably low temperature of the combustion gases. The subscale combustion chamber features a modular design that enables the easy application of a broad range of sensor equipment. Figure 3 shows the combustion chamber assembly.

The combustion chamber itself consists of the following segments:

- HF measurement ring,

- cylindrical combustion chamber,

- hot gas temperature measurement ring,

- segment for the insertion of $\mathrm{a} \mathrm{GH}_{2}$ cooling film for the nozzle,

- nozzle segment.

The total cylindrical chamber length was $290 \mathrm{~mm}$. The resulting characteristic chamber length is listed in Table 2 for both nozzle throat diameters. These values by far exceed the recommend characteristic chamber length for $\mathrm{LOX} / \mathrm{LH}_{2}$ combustion [6]. Therefore, a complete reaction was expected (Fig. 4).

The porous injector head used for this investigation consisted of 36 LOX injector tubes and a face plate made of a woven steel mesh similar to the Rigimesh ${ }^{\mathrm{TM}}$ material. The thickness of the face plate material was $24 \mathrm{~mm}$. The length of the LOX injector tubes was $45 \mathrm{~mm}$, while the inner and outer diameters were identical to the injector

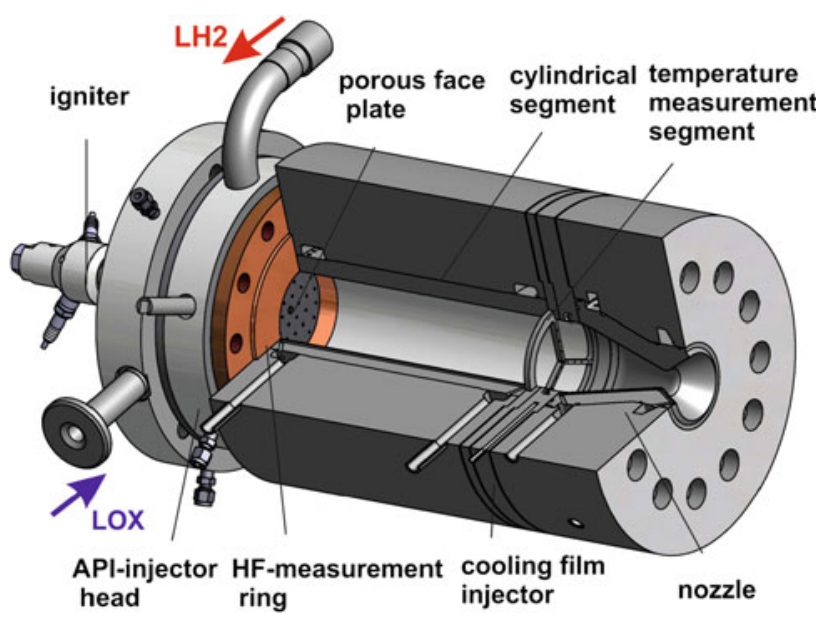

Fig. 3 Schematic of the $80 \mathrm{~mm}$ subscale combustion chamber 
Table 2 Nozzle configurations

\begin{tabular}{lll}
\hline Nozzle throat diameter & 14 & $\mathrm{~mm}$ \\
Nozzle contraction ratio & 32.6 & \\
Combustion chamber Mach number & 0.018 & \\
Combustion chamber main flow velocity & $\approx 30$ & $\mathrm{~m} / \mathrm{s}$ \\
Characteristic chamber length & $11.1^{\mathrm{a}}$ & $\mathrm{m}$ \\
\hline
\end{tabular}

a The characteristic length in case of the pre-burner is difficult to determine, as the nozzle throat area is hard to define accurately. The mentioned value of $\mathrm{L}^{*}$ is only a rough guideline to allow for a comparison with conventional main combustion chambers

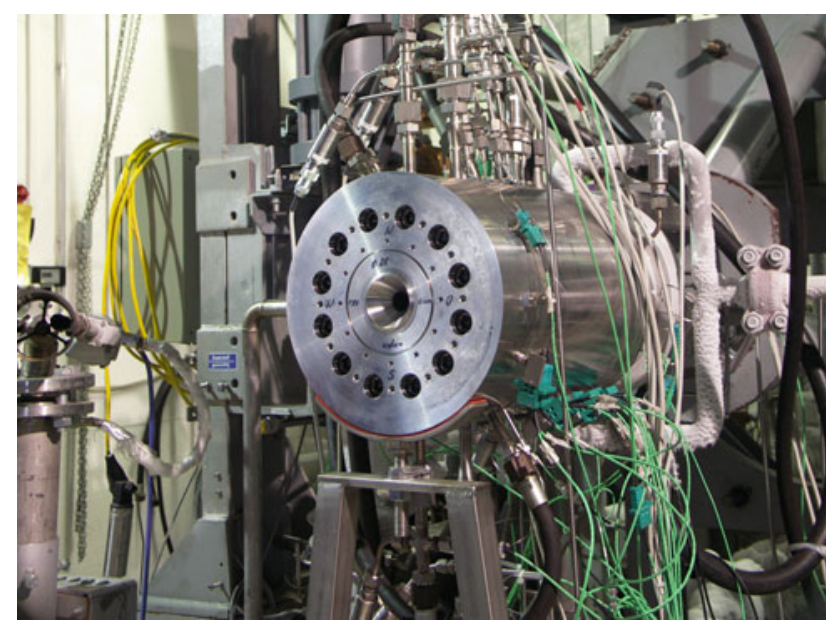

Fig. $480 \mathrm{~mm}$ subscale combustion chamber, mounted at the test bench P8

tubes used for MCC injector head investigations (inner diameter $1.5 \mathrm{~mm}$, outer diameter $2.0 \mathrm{~mm}$ ).

The thrust chamber is ignited using a $\mathrm{GOX} / \mathrm{GH}_{2}$ pilot flame injected through an igniter tube located in the chamber main axis. Figure 5 illustrates the injector head. The right hand side shows two magnified images of the face plate material. The wire diameter is about $0.6 \mathrm{~mm}$. The sintered steel mesh combines a high permeability with sufficient mechanical strength to withstand the mechanical stresses due to the pressure forces acting on the face plate. The hydrogen pressure losses during operation are determined solely by the permeability of the porous face plate. The oxygen pressure drop is controlled by an exchangeable orifice plate, which is mounted immediately upstream of the injector tubes. Although this orifice plate allowed for a tuning of individual injector elements, all test runs were performed with a common orifice diameter for all LOX tubes.

The cylindrical segment consists of a water cooled interior part manufactured from Inconel $600^{\circledR}$ and a massive outer liner made of stainless steel. The cooling of the interior part is done through a row of cylindrical channels and protects the sealing system and outer liner from
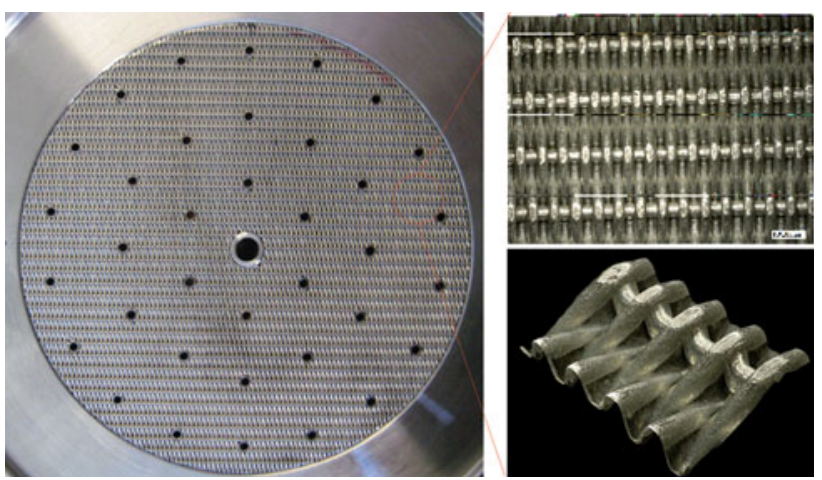

Fig. 5 API injector head of subscale chamber model "I"

overheating. Two collectors provide a uniform mass flow through all cooling channels. The mechanical loads are absorbed by the outer liner. This design enables the reliable operation of the combustion chamber in a width operation area concerning the combustion chamber pressure and the mixture ratio. A row of pressure sensors allows the determination of the pressure distribution along the combustion chamber main axis.

The conductive cooled HF measurement ring is integrated between the injector head and cylindrical segment. This region is characterized by low thermal loads and, therefore, conductive cooling reliably protects the test specimen. The 3 HF-pressure sensors and a row of thermocouples allow for the measurement of pressure oscillations as well as hot gas temperature distribution near the injector head. The nozzle segment has design similar to the cylindrical segment: a water cooled interior part from Inconel $600^{\circledR}$ and an outer part from stainless steel. For an additional protection, an $\mathrm{H}_{2}$ film injector has been implemented upstream of the nozzle segment.

\subsection{Test condition and results}

Table 3 shows the operating conditions of four test runs. The combustion efficiency $\eta_{\mathrm{c}^{*}}$ presented here is derived by a comparison of the actual and theoretical characteristic velocity $\mathrm{c}^{*}$. The latter is calculated using the NASA CEA code:

No corrections have been applied to the calculation of the combustion efficiency so far. The uncertainty in the calculation of the combustion efficiency sums up to at least $2 \%$. Therefore, the values presented here are only rough estimates and further analysis is required. The general tendency, however, shows that the combustion is essentially complete.

Figures 6 and 7 show pressure, mixture ratio and temperature plots of test runs 2 and 3, respectively. Stationary 
Table 3 Operating conditions

\begin{tabular}{lllll}
\hline Test run & $d_{\mathrm{t}} / \mathrm{mm}$ & $p_{\mathrm{cc}} / \mathrm{bar}$ & $\mathrm{ROF}$ & $\eta_{\mathrm{c}^{*}} / \%$ \\
\hline 1 & 14 & $\approx 218$ & 1 & n.a. \\
& $\approx 300$ & $0.6 \ldots 1$ & n.a. \\
2 & $\approx 217$ & 1 & 99.1 \\
& $\approx 300$ & $0.6 \ldots 1$ & $\approx 100$ \\
& $\approx 144$ & $0.8 \ldots 1$ & $\approx 100$ \\
3 & $\approx 220$ & 1 & 97.7 \\
& $\approx 330$ & 0.8 & 98.6 \\
\hline
\end{tabular}

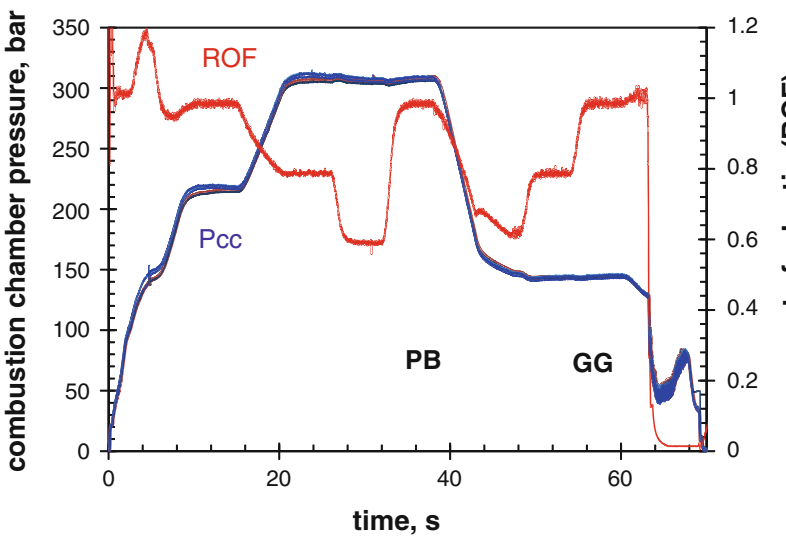

Fig. 6 Test sequence test run 2

operating conditions were maintained for at least $5 \mathrm{~s}$ to ensure thermal equilibrium of the system.

The hydrogen pressure drop across the porous face plate ranged between 1.5 and $5.5 \mathrm{bar}$, which is equivalent to 1-1.7\% of the corresponding mean chamber pressure.

Figure 8 shows the results of the dynamic pressure measurements shortly downstream of the injection plane for test runs 2 and 3 . The raw signal has been filtered by a $100 \mathrm{~Hz}$ high pass filter to account for various effects like sensor drift and also to eliminate pressure oscillations which can be attributed to the test bench. These contributions to the dynamic pressure signal are known to be below $100 \mathrm{~Hz}$. The dynamic pressure measured during test run 2 exhibits a large number of small amplitude pressure peaks which occur during the 300 bar phase of operation. Test run 3 exhibits a very smooth pressure signal, except for a single pressure peak at the start of the steady state 330 bar phase. The reason for these pressure peaks is not entirely clear. Local flame quenching is a possible explanation. The amplitude of these pressure spikes, however, is less than $2 \%$ of the mean chamber pressure. For most of the test time, the dynamic pressure remains well below $0.5 \%$ of the mean chamber pressure. No self-sustaining combustion instability was triggered during the test runs.

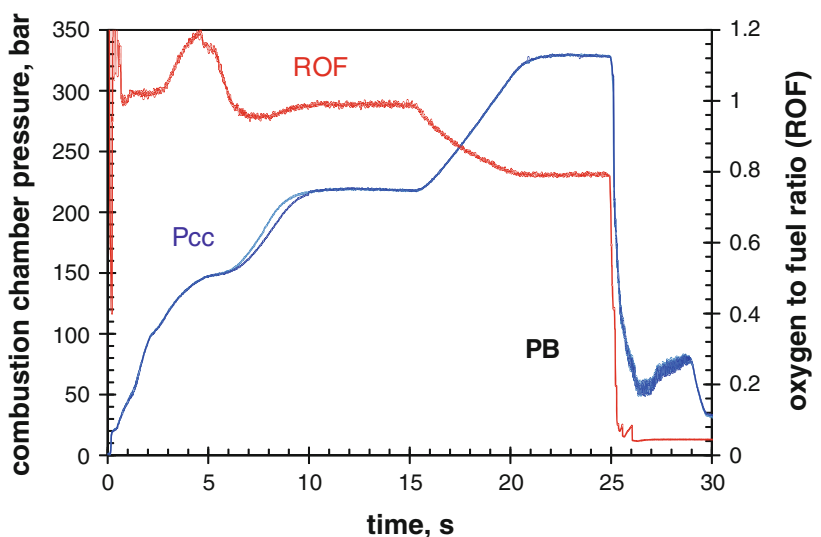

Fig. 7 Test sequence test run 3
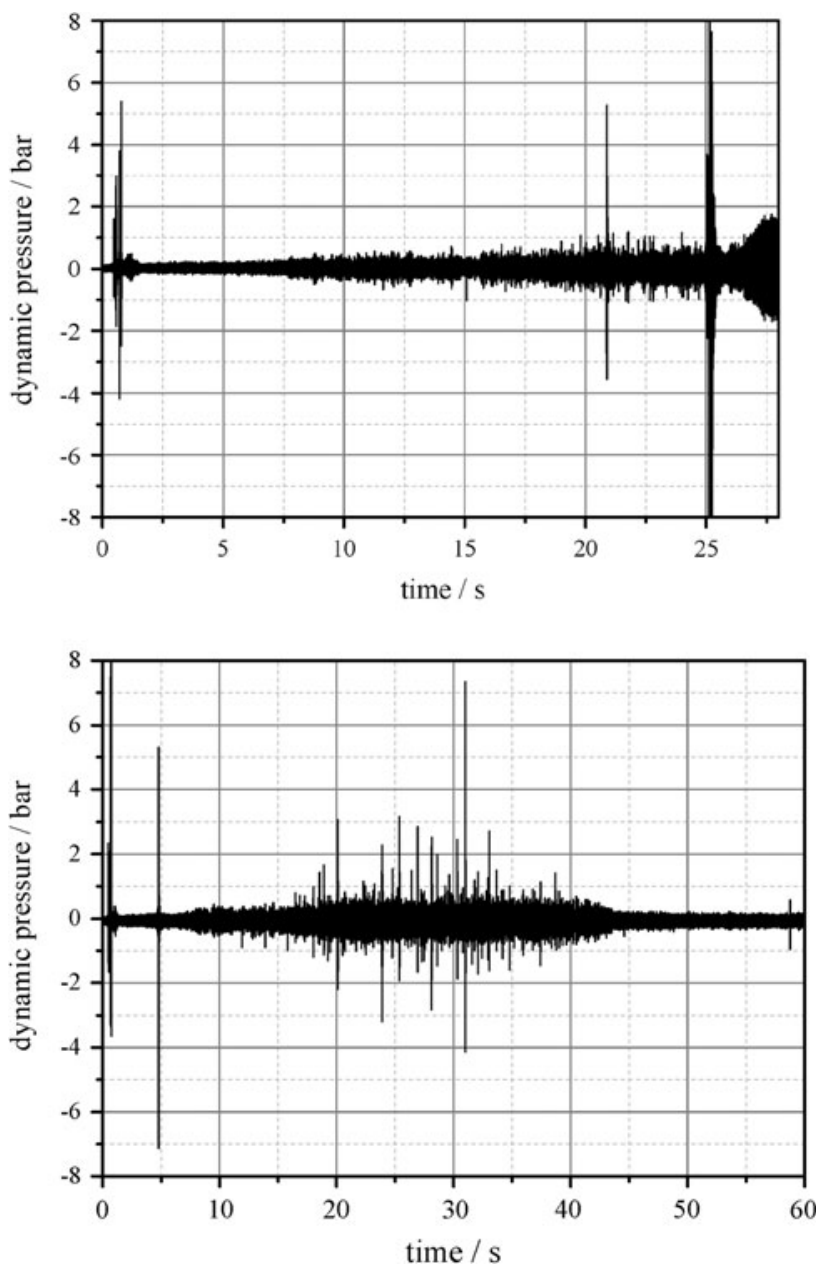

Fig. 8 Dynamic pressure measured during test run 2 (up) and hot run 3 (bottom) after application of a $100 \mathrm{~Hz}$ high pass filter

\section{SCORE-D hot combustion devices tests at P3.2 test facility}

This section summarizes the assessment by DLR [7] for the feasibility and the necessary modifications for the planned 
tests of the SCORE-D Hot Combustion Devices (HCD) and the limits of the existing High Pressure Thrust Chamber Test Bench P3.2 with respect to the SCORE-D HCD test requirements specified in [8]. These requirements have been derived from the following test objectives for the verification of the coupled $\mathrm{PB} / \mathrm{TCA}$ test configuration:

- demonstrating thermal and structural integrity, robustness and tightness,

- demonstrating ignition of the HCD with the required performance and reproducibility,

- demonstrating the specified performance of the HCD,

- determination of the internal loads,

- characterization of the HCD injection elements.

To cope with all of the test objectives, the SCORE-D HCD tests comprise two different test configurations, which are depicted in [9]:

- Configuration 0: PB (stand-alone).

- Configuration 1.1: PB + TCA.

\subsection{Test operation domain}

The steady-state operating conditions defined in the engine demonstration logic comprise the reference design point REF, the target demonstration points D1-D5 and the minimal and maximal values of the interface conditions (MIN and MAX). These steady-state operating conditions in terms of pressure, temperature and mass flow on all relevant external and internal interfaces are given in [9] and are not repeated here.

In addition to the operating points REF, MIN, MAX and D1-D5, three more points were defined to better assess the bench capabilities. These three operating points are called P3-1 to P3-3 and are defined by the performance data in [9]. Figure 9 illustrates all operating points.

\subsection{Test configurations for HCD tests}

All presented conditions are referring to the reference operating point. For configuration 0 , special attention has to be drawn to the fact that the $\mathrm{LH}_{2}$ delivered under high pressure by the test facility has to be conditioned to the desired PB inlet temperature (165 K at the REF point). For this purpose, the installation of a mixer on bench side has been regarded to produce $\mathrm{GH}_{2}$ of $165 \mathrm{~K}$ by mixing of $\mathrm{LH}_{2}$ (about $30 \mathrm{~K}$ ) and $\mathrm{GH}_{2}$ (about $270 \mathrm{~K}$ ), both available under high pressure at the $\mathrm{P} 3.2$, in a mixture ratio of about $\mathrm{LH}_{2} / \mathrm{GH}_{2}=1.7 / 1$. Figure 10 shows an existing mixer from the P3.2 inventory. A dedicated mixer-layout for the requested pressure and mass flows is presently being investigated to decide about the use of an existing mixer or a new design.

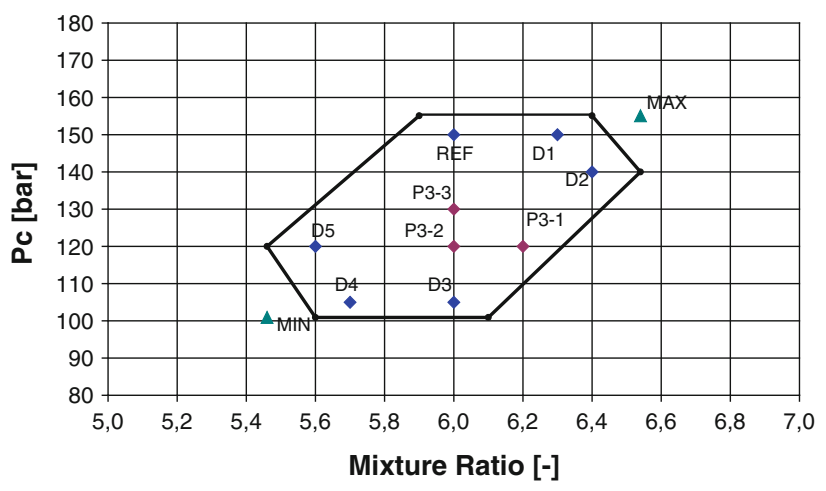

Fig. 9 Assigned operation envelope of SCORE-D [9]

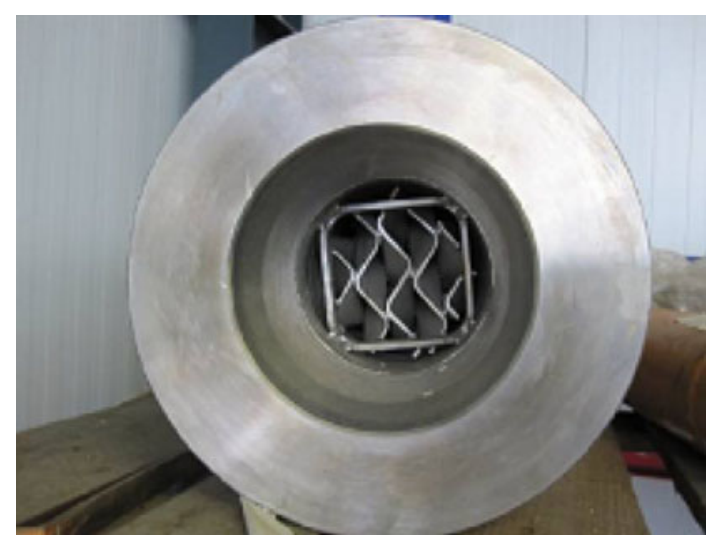

Fig. $10 \mathrm{LH}_{2}-\mathrm{GH}_{2}$ Mixer from P3.2 inventory [9]

\subsubsection{Configuration 0: PB (stand-alone)}

The $\mathrm{GH}_{2}$ inlet temperature for the $\mathrm{PB}$ is supposed to be regulated for each load point through the $\mathrm{LH}_{2} / \mathrm{GH}_{2}$ mixture ratio by means of fixed mass flow control values. The mixer is part of the specimen feedline and located directly in front of the PB injector head without an additional valve in between. This solution leads to short reaction times when the mixture ratio in the mixer has to be changed. Figure 11 presents this configuration.

\subsubsection{Configuration 1.1: $P B+T C A$}

Figure 12 shows a schematic of this $\mathrm{P} 3.2$ test configuration containing the SCORE-D PB and its TCA, the Nozzle Coolant Flow Adjustment Unit (NCFAU) and two venturi orifices. In the test facility representation of the engine, the pressure drop of the venturi orifices replaces the HPOT and HPFT pressure drop. The HPOT and HPFT temperature drop is replaced by different means, which still have to be decided, i.e.:

- enthalpy reduction by turbines or heat exchanger,

- lower PB exit temperature via lower PB mixture ratio, 


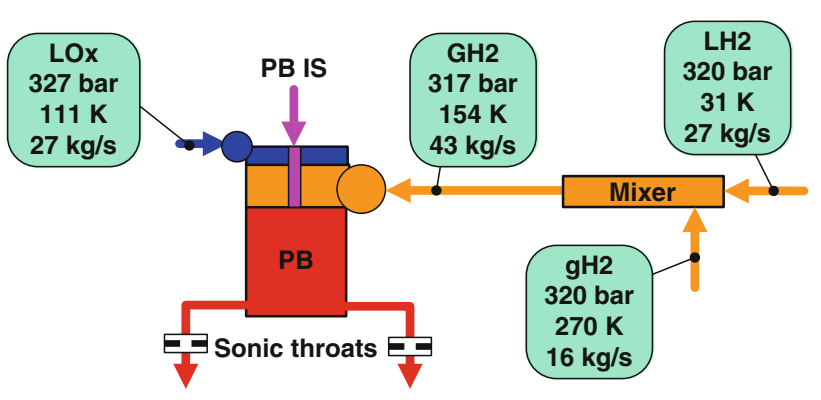

Fig. 11 Test configuration 0: SCORE-D PB with $\mathrm{LH}_{2} / \mathrm{GH}_{2}$ mixer in the feedline [9]

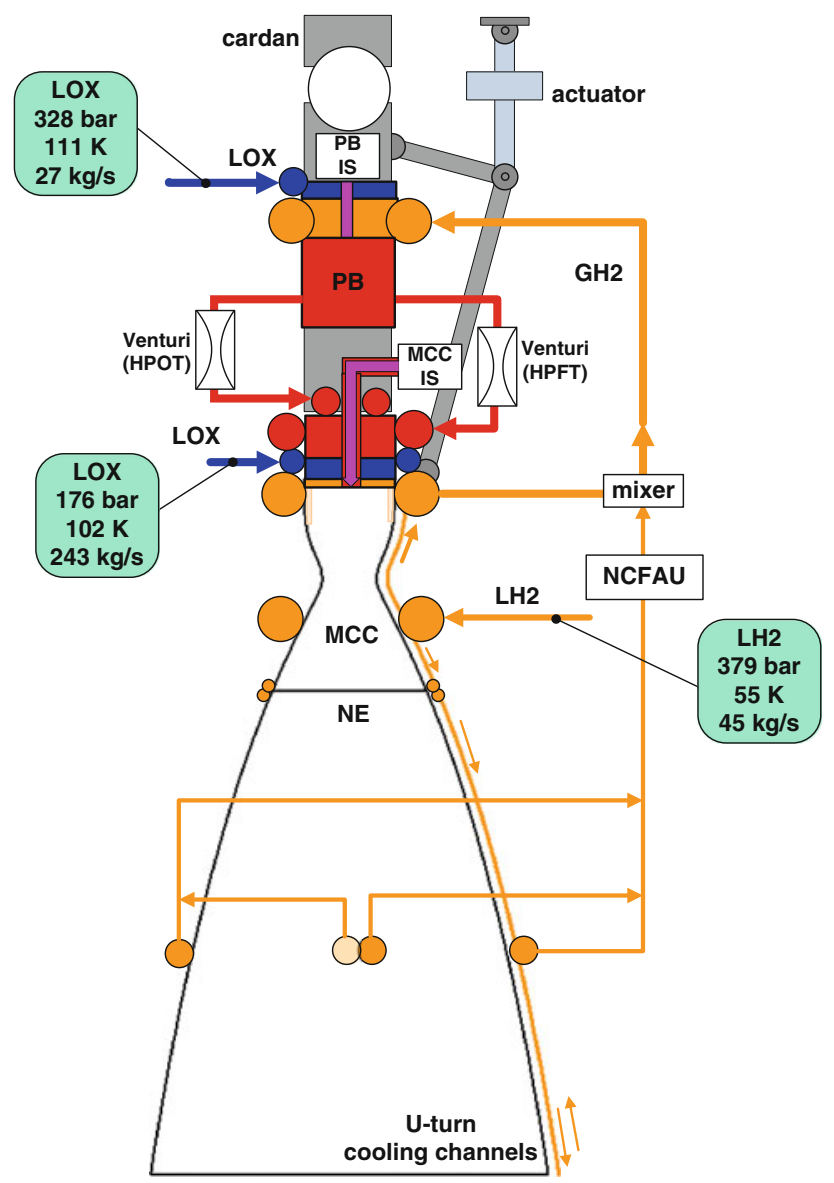

Fig. 12 Test configuration 1.1: SCORE-D PB and TCA; [9]

- lower PB exit temperature combined with water injection into the PB exit tubes.

The gimbal system (e.g. Cardan) and actuator strut are added to point out that thrust and side-load measurement are intended in these tests. Details of the temperature reduction devices in the $\mathrm{PB}$ hot gas exit ducts are not included in this picture. The conjunction of MCC and NE coolant flow takes place outside the MCC coolant exit manifold in a mixer. For this configuration $15 \mathrm{~s}$ of hot run time is envisaged.

\subsubsection{Configuration 1.2: $P B+T C, w / o N E$}

Since the MCC is equipped with a coolant inlet mid manifold, its coolant flow is split into an upward and a downward branch. As the NE is not installed in test configuration 1.2, the hydrogen from the lower MCC cooling branch exit has to be collected in an additional dummy manifold at $\varepsilon=8$ of the MCC. After passing the NCFAU, it is fed into the mixer, where it is combined with the cooling hydrogen of the upper branch of the MCC. Without heat pickup from the NE, the coolant flow from the lower MCC cooling branch to the mixer has a lower temperature compared to configuration 1.1 with $\mathrm{NE}$, resulting in a lower $\mathrm{GH}_{2}$ temperature at the $\mathrm{PB}$ inlet.

Probably, the $\mathrm{LH}_{2}$ mass flow rate to the lower MCC cooling branch can be reduced because the cooling needs of this part can be covered with a lower $\mathrm{LH}_{2}$ mass flow rate than $15 \mathrm{~kg} / \mathrm{s}$, which is the requested NE coolant flow in the reference point. This would ease the function to feed the PB with the requested hydrogen temperature of $154 \mathrm{~K}$.

Figure 13 shows a schematic of the potential P3.2 test setup without a preliminary decision how the temperature discrepancy is solved. The availability of cardan and actuator struts is not mandatory in this configuration. They can be replaced by a fixed mounting of the MCC because thrust and side-load measurements are not requested in the tests of configuration 1.2.

Note that configuration 1.2 is more complex than configuration 1.1 in terms of regulating the PB hydrogen inlet temperature. It was, however, investigated as back-up in case the nozzle extension manufacturing is delayed.

\subsection{Test bench modifications}

The P3.2 test bench (see left side on Fig. 14) is currently used for VINCI TC tests. In the past, this bench was used for HM60/Vulcain $1 \mathrm{TC}$ tests. The characteristics of its current status are documented in [10]. The DLR has reinvestigated the operation of the P3.2 test bench for two different extension levels [7], i.e.:

- Level 1 (rebuilding of HM60 test status):

- P3.2 safety pressure equipment technology from HM60 testing expanded to tank design limits

- Control valves operated critical during all conditions (sonic/cavitating)

- Additional cavitating venturis at feedline interfaces (bench/test-specimen) 


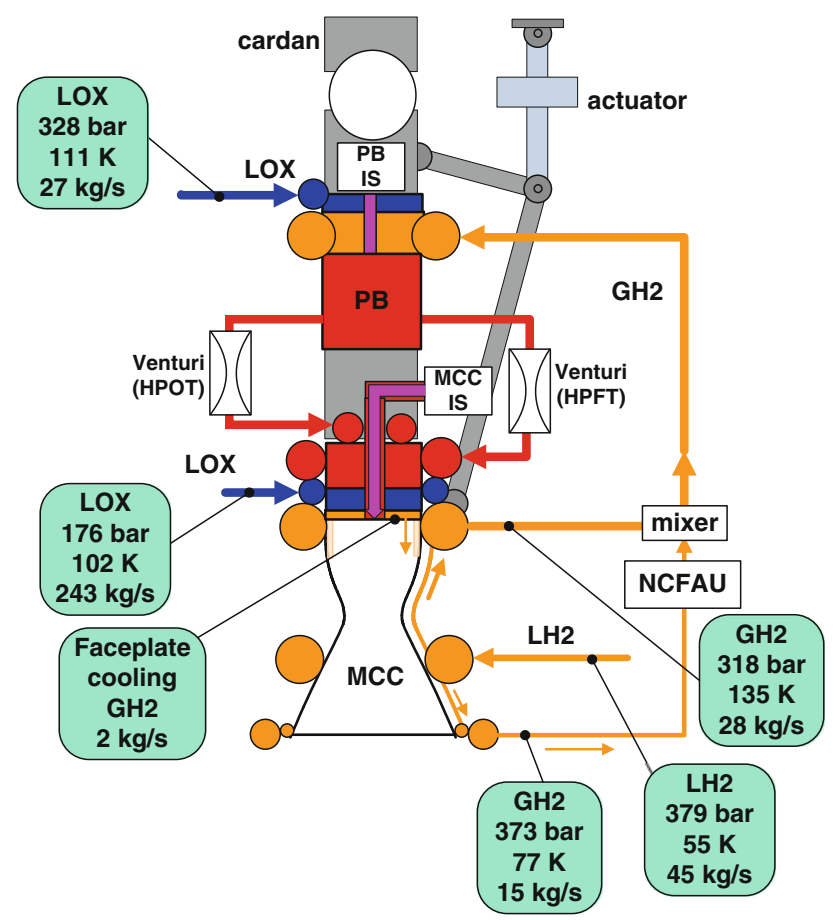

Fig. 13 Back-up test configuration 1.2: SCORE-D PB and TC w/o NE [9]

- Level 2 (extension of P3.2 equipment):

- P3.2 with new Power-Actuated Safety Relief Valves (EN ISO 4126-5)

- Control valves operated subcritical at highest load points

- No cavitating venturis

Based on these two different extension levels, different maximum bench pressure can be realized, as given in Table 7 in the Appendix. Note that for the high propellant I/F-pressures as required by the SCORE-D HCD tests, the operational pressure of the propellant tanks and piping is supposed to be equal to the respective design pressure.

However, this approach demands a "high safety standard" electronic pressure supervision device, which currently is not available a P3.2. In the European regulation EN ISO 4126-5, this equipment is designated as "Controlled Safety Pressure Relief System" (CSPRS). The details of this backfitting have to be agreed by the TÜV.

\subsubsection{Test cell}

The test cell of P3.2 accommodates the interfaces for supply lines to the combustion chamber together with the thrust stand for the horizontal installation of the combustion chamber. The test cell is erected behind a solid concrete wall to protect the supply systems, as can be seen in Fig. 14 on the right. The requirement of measuring the side loads calls for a dedicated thrust- and side-load-measurement device similar to the former Vulcain thrust measurement frame.

\subsubsection{Acoustic noise reduction system}

With the SCORE-D HCD hot tests, two different sources of acoustic noise are expected:

- PB:

- acoustic noise emission from (internal) combustion oscillations and from (external) combustion of the unburnt surplus- $\mathrm{H}_{2}$ leaving the $\mathrm{PB}$

- TC/TCA:

- acoustic noise emission from supersonic hot gas flow leaving the MCC/NE

For both cases, an acoustic noise reduction system (silencer) is required to meet the respective legal noise
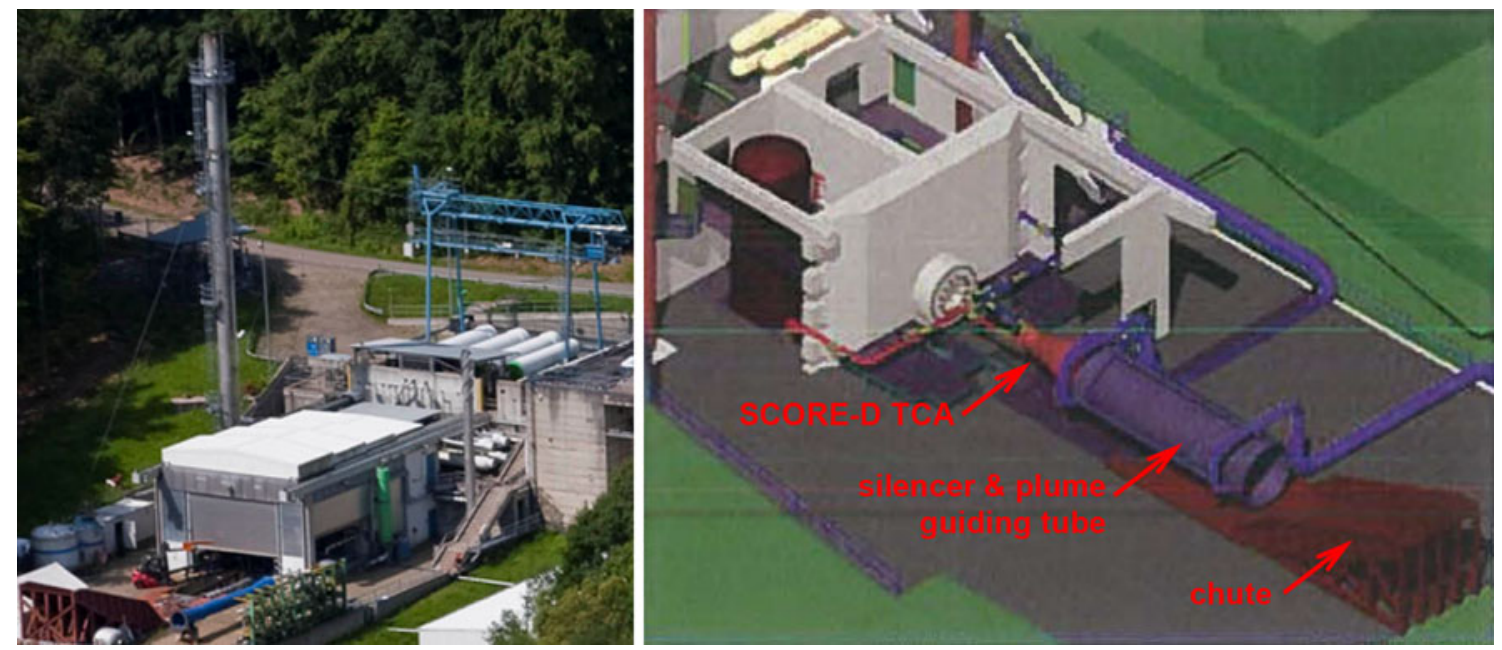

Fig. 14 Photo of actual P3.2 test bench (left) and 3D drawing of the SCORE-D integration in the test bench (right); [7] 
limits. The preferred noise reduction system is a water injection system with a plume guiding tube, which injects water (via a number of nozzles) into the plume and thus reduces the emitted acoustic noise. In Fig. 14 on the right, a possible assembly of the SCORE-D HCD and the silencer with a plume guiding tube is shown. The water injection system calls for additional water and electrical power supply.

\subsection{Assessment of SCORE-D HCD tests}

Level 1 extensions (P3.2 safety pressure equipment technology from HM60 testing) imply that the valves are operated critical during all conditions (sonic/cavitating) and additional cavitating venturis at feedline interfaces are used to decouple bench and test-specimen. With level 1 extensions, the throttled points MIN, D3, D4, and D5 are feasible for all configurations with minor modifications (new feedlines). For configuration 1.1, i.e. coupled PB/ TCA test, the operating points $\mathrm{P} 3-1$ to $\mathrm{P} 3-3$ were checked and also found to be feasible.

Level 2 extensions (P3.2 with new Power-Actuated Safety Relief Valves, valves operated subcritical at highest load points, and no cavitating venturis) will allow pushing the limits to reach D1 and D2 for configurations 0 and 1.2 and D2 only for configuration 1.1 because for D1 the required $\mathrm{LH}_{2}$-run tank pressure level is still above maximum acceptable tank operation pressure for this configuration.

Further extensions are necessary to operate all configurations at the REF point:

- LOX-wing:

- installation of 1,2 $\mathrm{m}^{3} / 400$ bar ex-P59 run tank

- $\mathrm{LH}_{2}$-wing:

- Installation of DN120-valves in feedline

- Negotiations for agreement with TÜV for a slight overrunning the maximum pressure (e.g. $5 \%$ ) for a fixed and small number of hot test runs (e.g. $5 \div 10$ tests)

Table 8 in the Appendix shows the assessment matrix of feasible load points within the assigned operation envelope of the SCORE-D HCD tests (see Fig. 9) for all three test configurations depending on the level of extension of the P3.2 test facility. The table was prepared together by DLR and Astrium and is courtesy of JPT.

\section{SCORE-D engine tests at P5 test facility}

At the time being the configuration of the test facility P5 is adjusted for tests with the engine Vulcain 2 for the ARTA 9 campaign. In this section, the needed modifications for
SCORE-D engine tests at the P5 are assessed and constraints are identified. For this assessment, the DLR has compared the recent configuration of the $\mathrm{P} 5$ to the characteristics of the SCORE-D presented in [11]. For this comparison, the Vulcain 2 engine test requirements were used, which reflect the current status of the technical performance of the P5 test bench. Since the key constraints for SCORE-D testing at P5 are the possible technical performance of the test bench, the Vulcain 2 data only served as a reference base.

The operation domain of the SCORE-D engine tests at P5 is consistent with the assigned operation envelope as depicted in Fig. 9. A test duration of $600 \mathrm{~s}$ is envisaged.

\subsection{Test configuration for engine tests}

Compared to the SCORE-D HCD tests at the P3.2 test facility, the engine test configuration exhibits two major differences:

- The engine is equipped with its turbo machinery to pump-fed the combustion chamber.

- The engine is installed vertical in the test cell.

The available height for the engine integration in the test cell is limited from the turbo pumps inlets of the Vulcain 2 engine, which are positioned about $0.5 \mathrm{~m}$ below the gimbal mounting plane. To overcome this height constrain, SNECMA proposes to short the feedlines so that the pump inlets move upwards. With the shortened feedlines, the distance between nozzle extension and test cell floor would become about $500 \mathrm{~mm}$ (see Fig. 15) according to the value of $4,080 \mathrm{~mm}$ for the length of the engine given in [12]. Figure 15 shows the integration of the SCORE-D engine in the test cell.

\subsection{Test bench modifications}

As described in Sect. 5.1 for the compatibility of the test cell to the test configuration a new arrangement of the LOX and $\mathrm{LH}_{2}$ feedlines, respectively, to their interfaces to the SCORE-D engine is necessary.

Within the fluid supply systems modifications are expected concerning TCA and PB igniter supply systems, e.g. a $\mathrm{GH}_{2}$ supply system for torch igniters, and the required GHe sub-systems for 50 bars and 100 bars. The main modification is the adaption of the $\mathrm{LH}_{2}$ and $\mathrm{LOX}$ purge and drain system due to power shedding and turbo pump bearing chill down requirements.

The thermal heat load on the bench deflector for the SCORE-D exhaust plume will be higher than the one caused by Vulcain 2. In the area of its first, second and third plates, the peak heat load calculated with CFD simulations is about 10-20\% higher for SCORE-D than in the case of Vulcain 2. The area with an increased thermal load 


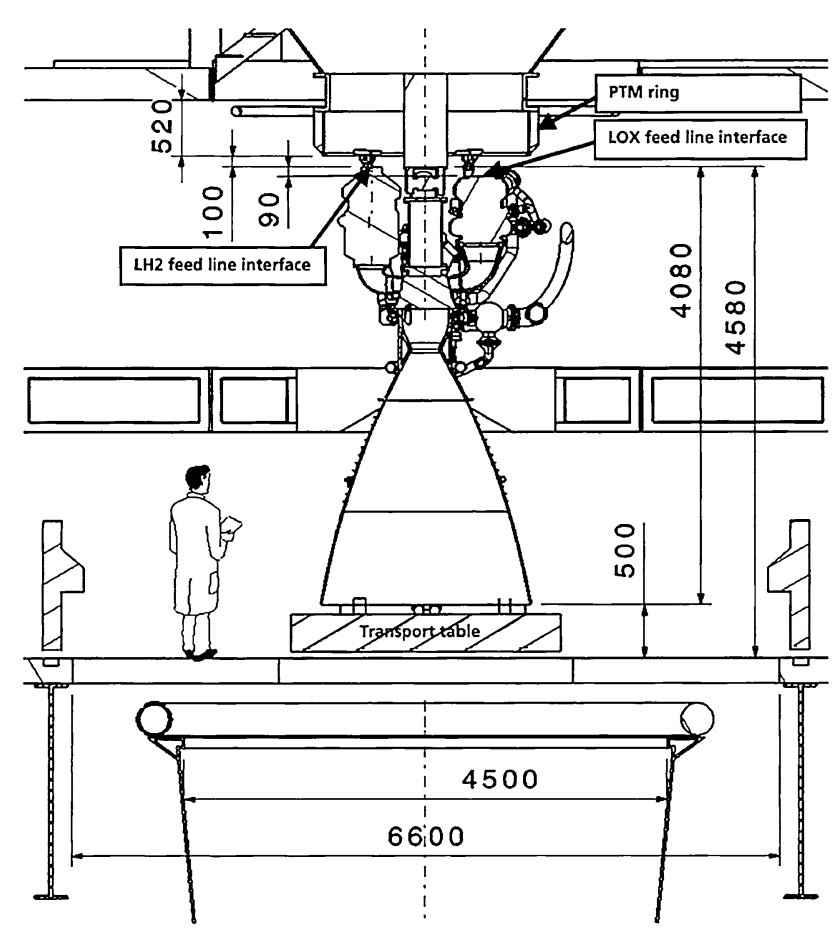

Fig. 15 Integration of SCORE-D in P5 test cell [12]

is also bigger in the case of SCORE-D and locally the thermal load maximal increase is about $40 \%$. The first, second and third plates are the ones with the highest thermal load. Due to the higher thermal load by SCORE-D on the deflector, DLR advises its modification to ensure the operation of SCORE-D at the P5. There are three scenarios in discussion:

1. Changing the provided water distribution to increase the protection of the impingement point by increase in the water mass flow rate provided by the water cannons (low cost).

2. Increasing the water pump capacity by adaption of the pump characteristic (high cost).

3. Changing the cooling mechanism at the area of the impingement point by an exchange of deflector plates (high cost).

Concerning the measurement, control, command and monitoring (MCCM) system, the main modifications are caused by commanding the SCORE-D engine per MIL BUS 1553 and the need of more LF and HF measurement channels compared to the Vulcain 2 engine. Extensions of the analog input channels for LF and HF measurement are required for the conducting of SCORE-D tests at P5. For the P5 MCCM hard constraints are imposed by the limit of $128 \mathrm{HF}$ measurement channels and the maximal summa rate of $5 \mathrm{M}$ Samples per second.

The monitoring system requires only minor modifications like the installation of mobile cameras in the test cell.
Also for the adaption of the electrical supply system for the torch igniter sparkling system and for the pyrotechnic igniter, some minor modifications were identified.

\subsubsection{Interface type}

All interfaces (bench side) are basically compatible to the Vulcain 2 interfaces. The tube connections have the Vulcain 2 flange diameter, sealing type and interface position. Electrical connectors are adjusted to Vulcain 2 electrical components (plug type, pin arrangement, fixation). Junction boxes have the dimension of the Vulcain 2 type and the compatible cable integration. If there is a nonconformity between the SCORE-D and Vulcain 2 engine interface, a modification is needed. A detailed interface comparison between SCORE-D engine and the Vulcain 2 engine is not yet available.

\subsection{Assessment of SCORE-D engine tests}

The DLR assesses the maximal SCORE-D test duration at the P5 test facility under the consideration of the existing $\mathrm{LOX} / \mathrm{LH}_{2}$ and water storages and the determination of limiting factors (Table 4).

- The P5 water storage has a capacity of $2,000 \mathrm{~m}^{3}$.

- The P5 LOX storage has a capacity of $179,000 \mathrm{~kg}$ (respecting maximal recommended tank fill level of $185 \mathrm{~m}^{3}$ and minimal fill level of $28 \mathrm{~m}^{3}$ as red line activation). Tank refilling after chill down for hot run is possible (Table 5).

For a $600 \mathrm{~s}$ hot run $183,000 \mathrm{~kg}$ of $\mathrm{LOX}$ is required, which is minimal over the P5 capacity. But with a minimal tank overfilling of $3.5-188.5 \mathrm{~m}^{3}$ this requirement could be realized.

- The P5 $\mathrm{LH}_{2}$ storage has a capacity of $35,700 \mathrm{~kg}$ (respecting maximal recommended tank fill level of $540 \mathrm{~m}^{3}$ and minimal fill level of $35 \mathrm{~m}^{3}$ as red line activation). Tank refilling after chill down for hot run is possible (Table 6).

The limiting factor for SCORE-D test duration is the LOX storage. The given test duration of $600 \mathrm{~s}$ in [11] is in

Table 4 Water need for a SCORE-D test [12]

\begin{tabular}{llll}
\hline Function & Duration & Mass flow & Need \\
\hline $\begin{array}{l}\text { Cooling during } \\
\text { firing }\end{array}$ & $600 \mathrm{~s}(723 \mathrm{~s})$ & $2,7501 / \mathrm{s}^{\mathrm{a}}$ & $1,650 \mathrm{~m}^{3}\left(2,000 \mathrm{~m}^{3}\right)$ \\
Total & $600 \mathrm{~s}(723 \mathrm{~s})$ & & $1,650 \mathrm{~m}^{3}\left(2,000 \mathrm{~m}^{3}\right)$ \\
\hline
\end{tabular}

a The same value as for Vulcain 2 engine tests is assumed for SCORE-D 
Table 5 LOX need for a SCORE-D test [12]

\begin{tabular}{lllr}
\hline Function & Duration & Mass flow $(\mathrm{kg} / \mathrm{s})$ & Need $(\mathrm{kg})$ \\
\hline Chill down & $3 \mathrm{~h}$ & & $33,000^{\mathrm{a}}$ \\
Start-up $^{\mathrm{b}}$ & $5 \mathrm{~s}$ & 300 & 1,500 \\
Firing & $600 \mathrm{~s}$ & 300 & 180,000 \\
Shut down $^{\mathrm{b}}$ & $5 \mathrm{~s}$ & 300 & 1,500 \\
Total & & & 216,000
\end{tabular}

${ }^{a}$ Need estimated with Vulcain 2 engine campaign M229 for 3 h chill down phase

${ }^{\mathrm{b}}$ Values are DLR assumptions (TBC)

Table $6 \mathrm{LH}_{2}$ need for a SCORE-D test [12]

\begin{tabular}{llll}
\hline Function & Duration & $\begin{array}{l}\text { Mass flow } \\
(\mathrm{kg} / \mathrm{s})\end{array}$ & Need \\
\hline Chill down & $3 \mathrm{~h}$ & & $2,900 \mathrm{~kg}^{\mathrm{a}}$ \\
Start-up $^{\mathrm{b}}$ & $5 \mathrm{~s}$ & 50 & $250 \mathrm{~kg}$ \\
Firing & $600 \mathrm{~s}(646 \mathrm{~s})$ & 50 & $\begin{array}{c}30,000 \mathrm{~kg} \\
(32,300 \mathrm{~kg})\end{array}$ \\
Shut down & & & $\begin{array}{l}250 \mathrm{~kg} \\
\text { botal }\end{array}$ \\
T & & 50 & $\begin{array}{c}33,400 \mathrm{~kg} \\
(35,700 \mathrm{~kg})\end{array}$ \\
& & &
\end{tabular}

${ }^{a}$ Need estimated with Vulcain 2 engine campaign M229 for 3 h chill down phase

b Values are DLR assumptions (TBC)

accordance with the P5 performance. DLR estimates also $600 \mathrm{~s}$ for maximal test duration under the declared conditions. The $\mathrm{LH}_{2}$ storage would be sufficient for maximal test duration of $646 \mathrm{~s}$ and the water storage would be sufficient for maximal test duration of $723 \mathrm{~s}$ under the declared conditions.

Table 9 in the Appendix summarizes the results of the assessment of feasible load points on the P5 test facility for SCORE-D engine tests within the assigned operation envelope (see Fig. 9). The table was prepared together by DLR and Astrium and is courtesy of JPT.

\section{Summary, conclusion and outlook}

The DLR Institute of Space Propulsion together with its partners from the European space industry contributes to ESA's FLPP program for the evaluation of innovative concepts for next generation European rocket engines. In the framework of these research activities, the test possibilities as well as new design solutions for the engine components are investigated.

The new API injector head design has been successfully tested at several steady-state operating conditions typical for pre-burner application. During these test runs, combustion chamber pressures up to 330 bars at mixture ratios ranging from 0.6 up to 1.0 have been achieved. A very stable and smooth combustion was demonstrated at advantageous pressure drops on the fuel side. The occasionally occurring low amplitude pressure peaks do not affect the stability behavior of the combustion chamber. The results show that a porous injector is a promising candidate for an injection concept for future pre-burners.

While DLR conducted the testing of its new injection system at the P8 test facility in a national frame parallel to the FLPP activities, Astrium has used the P8 test facility for test programs with the sub-scale assembly of $\mathrm{PB}$ and MCC for SCORE-D in preparation of the demonstration tests with the full-scale SCORE-D HCD. Together Astrium and DLR have assessed the feasibility of the P3.2 test facility to accommodate the SCORE-D HCD for the planned tests as well as its limits and the necessary modifications to meet the test requirements.

Three different test configurations of the SCORE-D HCD tests were assessed for their feasibility to be tested on the P3.2 test facility: configuration 0 (Stand-alone PB), configuration 1.1 (PB coupled with TCA) and configuration 1.2 (PB coupled with TC, w/o NE). The feasibility of stand-alone PB and coupled PB/TCA with or without NE is clearly given. A major part of the SCORE-D demonstration domain can be covered depending on the P3.2 extension level.

The compatibility of the P5 performance has been compared versus the SCORE-D requirements (as far as defined yet). This analysis was structured in fluid supply requirements, electrical requirements, test cell conditions, integration and disassembly requirements, MCCM requirements, etc. DLRs assessment of the P5 test facility reveals the necessary modifications for the operation of the SCORE-D engine. With these modifications and the present P5 performance, the SCORE-D demonstration domain can be completely covered. Based on this assessment DLR states the feasibility of SCORE-D engine tests at P5. A principle requirement for the necessary modifications from Vulcain 2 to SCORE-D test configuration must be their reversibility.

Acknowledgments The authors would like to thank Mr. Jérôme Breteau, ESA FLPP Propulsion Manager, and Mr. Richard Strunz, Astrium SCORE-D Project Manager, for their kindly contribution to the realization of this paper by means of granting access to the referenced documents and providing the approval to use parts of them inside this paper. Furthermore, the authors would like to thank the P8 team for their contributions during the test campaign.

Open Access This article is distributed under the terms of the Creative Commons Attribution License which permits any use, distribution, and reproduction in any medium, provided the original author(s) and the source are credited. 


\section{Appendix}

See Tables 7, 8, 9 and Fig. 16.

Table 7 P3.2 technical data for the two operation levels [9]

P3.2 Technical data

\begin{tabular}{|c|c|c|c|c|c|c|}
\hline & \multicolumn{2}{|l|}{ Volume } & \multirow[t]{2}{*}{$\mathrm{DN}(\mathrm{mm})$} & \multicolumn{2}{|l|}{ Pressure } & \multirow[b]{2}{*}{ Operation level 2 (bar) } \\
\hline & Geom. $\left(\mathrm{m}^{3}\right)$ & Usable $\left(\mathrm{m}^{3}\right)$ & & Design (bar) & Operation level 1 (bar) & \\
\hline \multicolumn{7}{|l|}{ Oxygen } \\
\hline Oxygen run tank & 4.5 & 3.35 & - & 350 & 335 & 350 \\
\hline $\mathrm{GN}_{2}$-HP-vessels & 21 & n.a. & & 800 & 720 & $720 / 800$ \\
\hline Oxygen feedline & - & - & 120 & 400 & 335 & 350 \\
\hline \multicolumn{7}{|l|}{ Hydrogen } \\
\hline Hydrogen run tank & 12 & 9.8 & - & 400 & 380 & 400 \\
\hline $\mathrm{GH}_{2}$-HP-vessels & 30 & n.a. & - & 800 & 720 & 800 \\
\hline Hydrogen feedline & - & - & 120 & 400 & 380 & 400 \\
\hline
\end{tabular}

Table 8 Assessment matrix of feasible load points on the P3.2 test facility as a function of the level of bench extension for all three configurations of SCORE-D HCD tests; Prepared by DLR and Astrium; Courtesy of JPT (FLPP Joint Propulsion Team)

\begin{tabular}{|c|c|c|c|}
\hline $\begin{array}{c}\text { Test } \\
\text { Configuration }\end{array}$ & Configuration 0: SCORE-D PB & Configuration 1.1: PB+TCA & Configuration 1.2: $\mathrm{PB}+\mathrm{TC}$ (w/o NE) \\
\hline \multicolumn{4}{|l|}{ Performance } \\
\hline $\begin{array}{l}\text { Level } 1 \\
\text { Rebuilding }\end{array}$ & \begin{tabular}{ll|l|}
1700 & \\
& & \\
\end{tabular} & ${ }_{170}^{180}$ & 1800 \\
\hline Level? & \begin{tabular}{|l|l|l|l|}
$\max$ & & \\
\end{tabular} & \begin{tabular}{|l|l|l|} 
& & Max \\
& 0 & 0 \\
\end{tabular} & $\theta_{0}^{\max }$ \\
\hline & ARE (9) OR & REF & REF \\
\hline & & 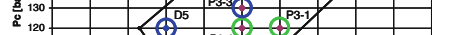 & \\
\hline & ${ }^{D 4}{ }^{33-2}$ & 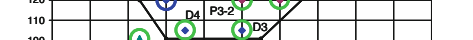 & $(04)^{-132.2}$ \\
\hline & 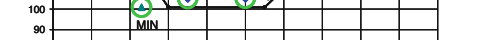 & \begin{tabular}{|l|l|l|l|l|l|l|l|l|l|l|l|l|} 
MiN & & & \\
\end{tabular} & - \\
\hline & 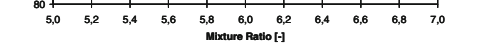 & 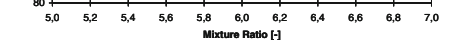 & 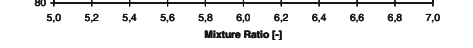 \\
\hline Test Du & $15 \mathrm{sec}-27 \mathrm{sec}$ & $15 \mathrm{sec}-24 \mathrm{sec}$ & $15 \mathrm{sec}-24 \mathrm{sec}$ \\
\hline $\begin{array}{c}\text { Main } \\
\text { Modifications } \\
\text { Level 1: }\end{array}$ & $\begin{array}{l}\text { Rebuild HM60 } \mathrm{LH}_{2} \text {-feedline + valves; } \\
\text { Use VINCI LOX-feedline for PB/or new; } \\
\text { Use } \mathrm{LH}_{2} / \mathrm{GH}_{2} \text {-mixer (HM60/VINCI/new); } \\
\text { Watercooled silencer+plume guiding tube }\end{array}$ & $\begin{array}{l}\text { Rebuild HM60 } \mathrm{LH}_{2}+\text { Lox feedlines; } \\
\text { Use VINCI Lox-feedline for PB/or new; } \\
\text { Need+type of T-hotgas reduction t.b.d.; } \\
\text { Thrustframe from HM60 (side loads); } \\
\text { Watercooled silencer+plume guiding tube }\end{array}$ & $\begin{array}{l}\text { Rebuild HM60 } \mathrm{LH}_{2}+\text { Lox feedlines; } \\
\text { Use VINCI Lox-feedline for PB/or new; } \\
\text { Use GH2-mixer to replace NE heatup; } \\
\text { Need+type of T-hotgas reduction t.b.d.; } \\
\text { Watercooled silencer+plume guiding tube }\end{array}$ \\
\hline $\begin{array}{l}\text { Additional } \\
\text { Extensions } \\
\text { Level 2: }\end{array}$ & $\begin{array}{l}\text { New power-actuated safety relief valves } \\
\text { for run-tanks (EN ISO } 4126-5) \text {; } \\
\text { Control valves operated subcritical at } \\
\text { highest load points (P8 experience); }\end{array}$ & $\begin{array}{l}\text { New power-actuated safety relief valves } \\
\text { for run-tanks (EN ISO } 4126-5 \text { ); } \\
\text { Control valves operated subcritical at } \\
\text { highest load points (P8 experience); }\end{array}$ & $\begin{array}{l}\text { New power-actuated safety relief valves } \\
\text { for run-tanks (EN ISO } 4126-5 \text { ); } \\
\text { Control valves operated subcritical at } \\
\text { highest load points (P8 experience); }\end{array}$ \\
\hline $\begin{array}{c}\text { Further } \\
\text { Extensions: }\end{array}$ & $\begin{array}{l}\text { Installation of } 1.2 \mathrm{~m}^{3} / 400 \text { bar ex P-59 LOX } \\
\text { run tank for PB LOX supply; }\end{array}$ & $\begin{array}{l}\text { Installation of } 1.2 \mathrm{~m}^{3} / 400 \text { bar ex P-59 LOX } \\
\text { run tank for PB LOX supply; } \\
\text { Pressure upgrade (TÜV) of } \mathrm{LH}_{2}+\text { LOX run } \\
\text { tank according ISO21009-1(E); } \\
\text { Pressure upgrade of feedlines + } \\
\text { installations (DN120 valves); }\end{array}$ & $\begin{array}{l}\text { Installation of } 1.2 \mathrm{~m}^{3} / 400 \text { bar ex P-59 Lox } \\
\text { run tank for PB Lox supply; } \\
\text { Pressure upgrade (TÜV) of } \mathrm{LH}_{2}+\text { LOX run } \\
\text { tank according ISO21009-1(E); } \\
\text { Pressure upgrade of feedlines + } \\
\text { installations (DN120 valves); }\end{array}$ \\
\hline Sta & feasible & feasible & feasible \\
\hline
\end{tabular}


Table 9 Assessment of feasible load points on the P5 test facility for SCORE-D engine tests; Prepared by DLR and Astrium; Courtesy of JPT (FLPP Joint Propulsion Team)

Test configuration

\section{Performance}

Test duration

Main modifications

\section{Engine}

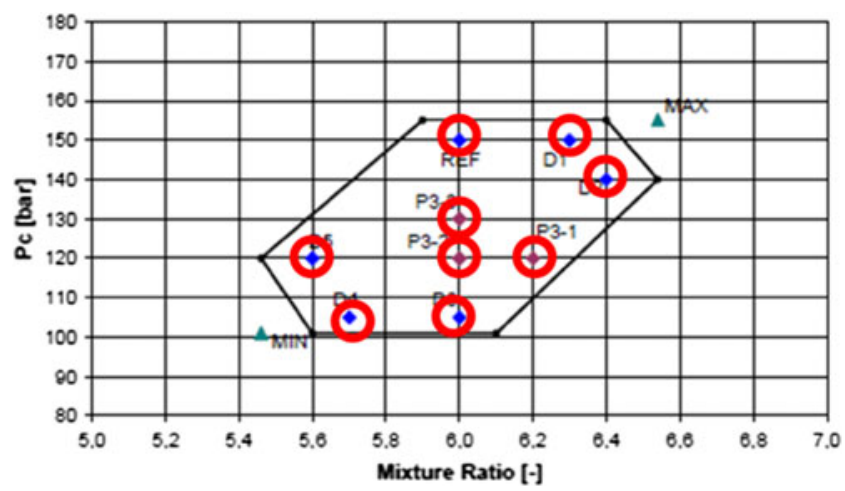

$600 \mathrm{~s}$

$\checkmark$ Deflector and guide-tube tailoring

$\checkmark$ Handling tools tailoring

$\checkmark$ LOX and $\mathrm{LH}_{2}$ feedlines arrangement

$\boldsymbol{V}$ Purge and drain system for $\mathrm{LOX}$ and $\mathrm{LH}_{2}$

$\checkmark \mathrm{GH}_{2}$ supply system for torch igniters

$\checkmark$ GHe sub system for 100 bar

$\checkmark$ GHe sub system for 50 bar

$\checkmark \mathrm{GN}_{2}$ sub system for $1.5 \mathrm{bar}$

$\checkmark$ GOX need for test and supply system

$\checkmark$ Electrical supply system for torch igniter sparkling system

$\checkmark$ Electrical supply system for pyrotechnic igniter

$\boldsymbol{V}$ Analog input channels for LF measurement

$\checkmark$ Analog input channels for HF measurement

$\checkmark$ Commanding per MIL BUS 1553

$\checkmark$ Test cell camera system

Feasible
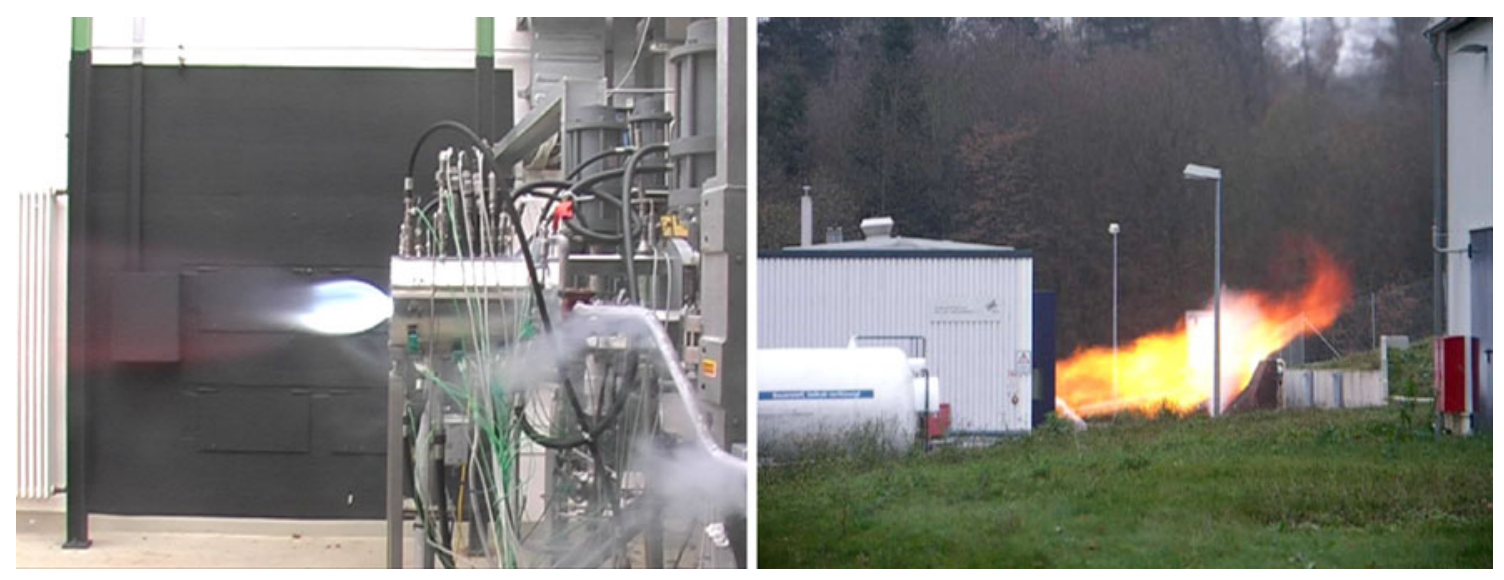

Fig. 16 DLR subscale combustion chamber model "I" during hot fire tests at the P8 test bench 


\section{References}

1. Kauffmann, J., Pinard, D.: ESA's next generation launcher: status of the FLPP launch system concept investigations. In: IAC10.D2.4.2, 61st International Astronautical Congress (2010)

2. Alliot, P.: System engineering presentation of the European staged combustion demonstrator SCORE-D. In: IAC-11.C4.1.11, 62nd International Astronautical Congress (2011)

3. Gubanov, B.I.: Триумф и трагеДия Энергии, Размышления главного конструктора; NIER, Нижний НовгороД (1998)

4. Pavli, A.J., Kacynski, K.J., Smith, T.A.: Experimental Thrust Performance of a High-Area-Ratio Rocket Nozzle. Technical Report, NASA Lewis Research Center (1987)

5. Powell, W.B.: Simplified Procedures for Correlation of Experimentally Measured and Predicted Thrust Chamber Performance, NASA-CR-131519 (1973)

6. Huzel, D., Huang, D.: Modern Engineering for Design of LiquidPropellant Rocket Engines. AIAA; ISBN: 1-56347-013-6 (1992)
7. Kraft, V.: SCORE-D: Assessment of P3.2 test bench adaptation. FLP-TN-10000-H-0004-DLR; Iss. 02; 07.09.2011 (not publicly available)

8. FLP-GSS-11000-X-0001-ASTG: Preliminary TCA Ground Support Specification; Iss. 02; 19.1.2011, LOX/Hydrogen TCA (not publicly available)

9. Strunz, R.: Synthesis Report P3.2 Test Facility Demo Logic KP; FLP-TN-22161-H-0010-ASTG; Iss. 01; 28.11.2011 (not publicly available)

10. FLP211-JPT-TNT-0091: European Test Benches Identification and Mandatory Modifications; FLPP2.1.1-TN91-WP9230 (not publicly available)

11. FLP-BFS-10000-H-5000-SN: SCORE-D Engine preliminary test bench functional specification; Iss. 1; 11.03.2011 (not publicly available)

12. Reinhold, J.: Conceptual design of P5 test facility modification; FLP-TN-10000-H-0002-DLR, Iss. 04; 22.12.2011 (not publicly available) 